\title{
EL ROL DEL RAZONAMIENTO ABDUCTIVO EN EL RAZONAMIENTO PROBATORIO DEL DERECHO: UNA PERSPECTIVA ORIENTADA HACIA LA PRÁCTICA ${ }^{1}$
}

\author{
José ENRIQUe \\ Sotomayor Trelles \\ Investigador del Centro de \\ Investigación Interdisciplinar \\ Ciencia y Sociedad (CIICS) de \\ la Universidad de Ciencias y \\ Humanidades (UCH), Lima, Perú. \\ jesotomayorवuch.edu.pe
}

\author{
Gabriel Eduardo \\ USCAMAYTA \\ Abogado por la Universidad Andina \\ del Cusco. Posgrado en Defensa \\ de la Competencia y Propiedad \\ Intelectual por la Universidad \\ Católica San Pablo, Perú. \\ guscamaytaaprestonlegal.org
}

\author{
Niels J. Apaza Jallo \\ Abogado por la Universidad \\ Nacional del Altiplano, con \\ segunda especialidad en \\ Argumentación Jurídica por la \\ Pontificia Universidad Católica del \\ Perú y predocente en la Pontificia \\ Universidad Católica del Perú. \\ niels.apazalapucp.edu.pe
}

Resumen

El presente artículo parte de una revisión y relativización de la tajante distinción entre contexto de descubrimiento y contexto de justificación, originada en la filosofía de la ciencia del empirismo lógico y presente como un presupuesto de varios estudios sobre la argumentación jurídica. A continuación, analiza la propuesta de desarrollar una lógica del descubrimiento para el contexto de descubrimiento, una de cuyas principales herramientas sería el razonamiento abductivo. Finalmente, aplica los alcances de tal discusión al razonamiento probatorio jurídico, a partir del análisis de algunos casos.

Palabras clave: contexto de descubrimiento; contexto de justificación; lógica del descubrimiento; razonamiento abductivo; razonamiento probatorio.

1 Una versión previa de este trabajo fue revisada por el profesor Miguel León Untiveros, quien formuló valiosas observaciones y sugerencias. Asimismo, agradecemos los comentarios y críticas planteadas por los evaluadores anónimos, pues nos permitieron identificar errores e imprecisiones a lo largo del texto. 


\begin{abstract}
The article departs from an analysis and relativization of the sharp distinction between the context of discovery and the context of justification, originated in the philosophy of science of logical empiricism, but present as a presupposition of several studies on legal argumentation. Next, it analyzes the proposal to develop a logic of discovery for the context discovery, one of whose main tools would be abductive reasoning. Finally, it applies the scope of such discussion to legal evidential reasoning, developing the analysis of some cases.
\end{abstract}

Keywords: context of discovery; context of justification; logic of discovery; abductive reasoning; evidential reasoning. 


\section{Introducción}

El presente trabajo tiene tres objetivos: (i) debilitar la distinción tajante entre contexto de descubrimiento y contexto de justificación, (ii) analizar la estructura y función de la abducción en el razonamiento probatorio y (iii) aplicar todo ello al análisis de casos que involucran razonamiento probatorio, extraídos de la jurisprudencia penal peruana.

Para el logro de tales objetivos, como punto de partida, explicaremos nuestra posición sobre por qué la abducción no ha recibido un estudio detenido en el derecho - en comparación con el razonamiento deductivo, inductivo, analógico e, incluso, conductivo- a lo largo del tiempo y cómo es que ahora aparece como una herramienta potente para explicar parte de nuestro razonamiento sobre los hechos, principalmente en el contexto de descubrimiento.

A continuación, explicaremos qué se puede entender por razonamiento abductivo y cuál es su estructura mediante algunos ejemplos.

Finalmente, defenderemos la tesis de que la incorporación de un análisis sobre la abducción nos lleva, desde una teoría de la argumentación jurídica centrada en el contexto de justificación, hacia una compleja teoría sobre la racionalidad en el análisis y toma de decisiones, con lo que se incorpora la racionalidad del proceso de descubrimiento. Esta tesis será ejemplificada a partir del análisis de dos casos.

Como apunte previo, es importante precisar que el artículo no desarrolla de forma detallada todas las críticas que se han formulado a la distinción entre contexto de descubrimiento y contexto de justificación. Esta es una tarea que, aunque necesaria y prometedora, no puede ser abordada aquí. En su lugar, se muestra que dicha distinción puede ser cuanto menos debilitada o relativizada, y que al hacerlo se puede obtener una perspectiva más amplia y fructífera sobre el razonamiento relacionado con cuestiones de hecho en un caso.

\section{Sobre la dicotomía contexto de descubrimiento - contexto de justificación}

Algunos de los autores asociados con lo que Manuel Atienza (2020) llama "teoría estándar de la argumentación jurídica" (TAJ) influyente hasta la actualidad, partieron de la distinción entre el contexto de justificación (CJ) y el contexto de descubrimiento (CD), con la finalidad de limitar su objeto de estudio (Atienza, 2013, pp. 114-116). Tal orientación no es excluyente de la TAJ producida en el mundo hispanoamericano, sino que también parece ser una característica presente en algunas aproximaciones de teoría del derecho en el mundo anglosajón (Anderson, 1996, cap. 1). De hecho, la investigación de Anderson (1996) le lleva a identificar a Richard Wasserstrom y Neil MacCormick como dos de los más conocidos defensores de la distinción aplicada al derecho (pp. 11 y ss.). En efecto, MacCormick es claro al señalar que el proceso que le interesa estudiar es el de la argumentación entendida 
como justificación, esto es, como el ofrecimiento público de un conjunto de razones que fundamentan una decisión de acuerdo a derecho (MacCormick, 2003/1978, pp. 15 y ss.).

Quienes aceptaban esta distinción, y concentraban sus esfuerzos en el CJ, podían centrarse en las razones justificativas de una decisión, dejando de lado las razones que explicaban el proceso psicológico-cognitivo de formación de la misma. De hecho, tal como parece afirmar García Figueroa, este enfoque tiene una connotación estratégica que permitió a los teóricos del derecho reducir su labor cognitiva, eligiendo una de las dimensiones (contextos) y dejando de lado la otra a ramas más especializadas como la psicología o la sociología jurídica (Gascón Abellán y García Figueroa, 2015, pp. 140141). El problema es que, como apunta Anderson, la psicología del proceso de decisión judicial es una de las ramas menos estudiadas de las teorías sobre la decisión judicial (Anderson, 1996, p. 1).

Ahora bien, ¿a qué nos referimos, con exactitud, cuando hablamos de CJ y CD? La distinción se origina en el contexto de la filosofía de la ciencia del empirismo lógico. Autoras como Atocha Aliseda (2006, p. 6) o Jutta Schickore (2018) coinciden en sostener que fue Hans Reichenbach quien propuso la dicotomía en la década de 1930. En su formulación temprana, el CJ hace referencia a la formulación sistemática de una teoría científica, entendida como un conjunto de proposiciones sustentadas en razonamientos, mientras que el CD se refiere a la concepción de una idea, entendida como un proceso psicológico por parte del investigador (Reichenbach, 1938, pp. 3-16). No obstante, Aliseda matiza la distinción al proponer dos sentidos en que se aborda el CD: un sentido amplio y uno restringido. En sentido restringido el CD solo hace referencia a la concepción inicial de una idea, mientras que el sentido amplio incluye todo el proceso que va desde la concepción de una idea hasta el momento previo a su formulación como una teoría sistemática.

En la teoría del razonamiento jurídico se emplea esta distinción para identificar, indistintamente, dos cuestiones: (i) los criterios de corrección de una decisión y (ii) los factores que condicionan tal decisión. Dicha distinción ha sido utilizada como un instrumento de la argumentación jurídica para evaluar las decisiones judiciales, teniéndose preferencia por los criterios de corrección de la decisión (CJ) frente a los criterios condicionantes de la misma (CD). Ello se justifica en tanto los criterios de corrección pueden ser controlables interpersonalmente, en la medida que se concretizan en algún documento público (una sentencia, por ejemplo), mientras que los factores que condicionan la decisión necesitan de estudios empírico-psicológicos para ser analizados (Pino, 2017, p. 39).

Ahora bien, llegados a este punto, resulta pertinente recordar que la distinción entre CJ y CD no se origina de la teoría del Derecho. Esta es, más bien, resultado de una importación desde la parcela de la filosofía de la ciencia, donde se empleó desde inicios hasta 
mediados del siglo XX, en el periodo de auge y progresivo declive del empirismo lógico (Schikore \& Steine, 2006, p. vii). Es precisamente la filosofía de la ciencia un lugar en el que, desde hace varios años, la distinción se ha ido atenuando, debido a una importante variedad de críticas y nuevas investigaciones (para un repaso sobre diversas estrategias de distinción, asunciones compartidas y el desarrollo de algunas críticas y refinamientos de la distinción en la filosofía de la ciencia, véase Hoyningen-Huene, 2006, pp. 119-131). De hecho, consideramos que la misma suerte de progresivo debilitamiento de la distinción se viene desplegando en la teoría del Derecho (en esa línea véase, por ejemplo, Accatino, 2002). Veamos, entonces, de forma esquemática, algunos sucesos en la filosofía de la ciencia que explican la progresiva atenuación a la que hemos hecho referencia.

Las primeras concepciones sobre la distinción entre CD y CJ indicaban que el primero de estos conceptos daba cuenta de los procesos de generación de hipótesis y teorías, mientras que el segundo remitía a la comprobación y validación de estas. De hecho, se creía que no existían reglas lógicas que permitan construir una máquina del descubrimiento (discovery machine) que imite la actitud creativa de los genios que planteaban hipótesis, cuestión que era distinta cuando se hablaba del contexto de justificación, que sí era un área que podía ser rigurosamente estudiada (Arabatzis, 2006, p. 215).

Theodore Arabatzis afirma que esta distinción estaba ligada a las siguientes premisas: primero, que la filosofía de la ciencia era una empresa normativa que buscaba generar criterios capaces de establecer cuándo algo era ciencia y cuándo no; segundo, que se entendía que el CD estudiaba la "creatividad científica"; y, tercero, y en línea de lo anterior, que no existían reglas para mejorar la "creatividad científica" (Arabatzis, 2006, p. 215).

Uno de los argumentos contemporáneos empleados para atenuar la concepción clásica de la separación entre CD y CJ consiste en mostrar que la ciencia, al entender el descubrimiento como un logro epistémico que permite revelar la existencia de algo, presupone que tal descubrimiento solo tiene validez después de haber convencido (en el plano de la justificación) a la comunidad científica relevante, de acuerdo con criterios establecidos endógenamente por dicha comunidad (Arabatzis, 2006, p. 217). Es decir, que el descubrimiento de algo depende de la justificación de ese algo, ya que es a partir de la justificación que se utilizarán las reglas y se cumplirá con los procedimientos impuestos por la comunidad para darle consistencia, y como tal, si supera el umbral de racionalidad impuesto, se tendrá a este algo como descubierto. Arabatzis (2006) justifica lo anterior señalando que “(...) una mera hipótesis, en el sentido de que una nueva entidad existe, no calificaría como un descubrimiento de tal entidad. La justificación de una hipótesis tal sería una característica constitutiva del descubrimiento" (p. 217, traducción propia). Desde esta perspectiva, parece que la justificación es ya parte del descubrimiento. 
En el terreno de la teoría del Derecho, la dicotomía CJ/CD también empezó progresivamente a atenuarse y a perder fuerza. Por ejemplo, Atienza (2017) señala que la TAJ —al centrarse exclusivamente en el CJ- es probable que “(...) haya limitado excesivamente el alcance de la teoría, e incluso que haya impedido una comprensión cabal del razonamiento justificativo si es que la distinción en cuestión no puede trazarse de manera estricta: o sea, si hubiera elementos de carácter explicativo que jugaran también un papel en la justificación. Y esto último es lo que parece suceder" (p. 16). Y, en efecto, tal como sucedió en la filosofía de la ciencia, en el derecho parece que también se pueden extraer algunas razones explicativas del discurso justificativo.

Por su parte, Anderson recuerda que en la tradición del realismo jurídico estadounidense existía una preocupación por el proceso mental que derivaba en la decisión judicial. Esta preocupación llevó a autores como Jerome Frank a interesarse en las actividades mentales desplegadas por el juez para tomar una decisión, de forma tal que se pueda identificar sesgos o prejuicios en el razonamiento. La identificación era, desde luego, instrumental, pues lo más importante era desarrollar mecanismos de control para evitar el ingreso de factores irracionales en el proceso de razonamiento (Anderson, 1996, p. 5). De esta forma, se puede encontrar una nueva crítica a la distinción tajante entre CD y CJ, en la medida que la misma no nos permite desarrollar una más integral teoría sobre la racionalidad en el proceso de análisis y toma de decisiones jurídicas. Al adoptar una distinción tajante entre CD y CJ corremos el riesgo de dejar el proceso de descubrimiento en una suerte de caja negra que no es sometida a los estándares de racionalidad que aplicamos al CJ, y ello puede tener como resultado una perspectiva parcial sobre la racionalidad del razonamiento jurídico.

También Giorgio Pino (2017) ha desarrollado tres argumentos que permiten sostener la necesidad de atenuar de la dicotomía entre CJ y CD en el razonamiento jurídico: (i) el curso dialéctico de la interpretación; (ii) la fuerza civilizadora del contexto de justificación; y, (iii) las ideologías jurídicas. Veamos con más detalle cada uno de estos argumentos.

Con referencia al curso dialéctico de la interpretación, Pino entiende que interpretar consiste en asignar sentido a disposiciones normativas (en el mismo sentido Guastini, 2018; Canale, 2019, entre muchos otros). Dicha asignación corresponde a un ejercicio volitivo que implica elegir entre alguno de los sentidos de entre todos los disponibles y que son adscribibles a una disposición. Podemos entender que el proceso de interpretación implica, en líneas generales, tres momentos hasta la elección final del sentido de la disposición normativa: (i) la interpretación hipótesis; (ii) la dilucidación de las interpretaciones disponibles; $y$, (iii) la interpretación producto. Estos momentos se recogen en el siguiente gráfico: 


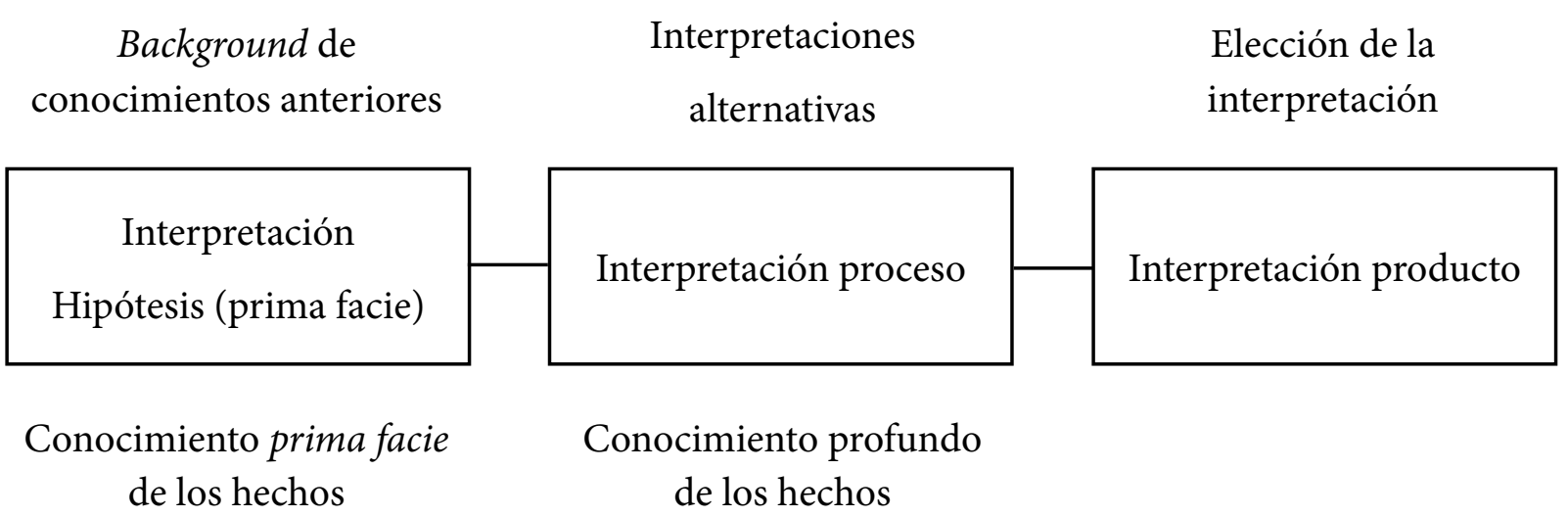

Gráfico 1: Proceso interpretativo (Giorgio Pino) Fuente: elaboración propia

Puede entenderse que el fenómeno interpretativo se inicia con una hipótesis inicial sobre la interpretación de una disposición normativa, de acuerdo con un primer acercamiento a los hechos del caso concreto. Isabel Lifante, siguiendo a Gianformaggio, ha llamado a este primer momento "interpretación noética”. En este “(...) se produce una captación del significado como un pensamiento intuitivo, es decir, una captación intelectual inmediata de una realidad inteligible (...)" (Lifante, 2019, p. 2). Ahora bien, parece que se descubre la mejor interpretación en el transcurso del proceso judicial, cuando el juez conoce mejor los hechos y analiza otras posibles interpretaciones de la disposición (o disposiciones) que las partes eventualmente aportan en sus argumentos. Después de todo este proceso, el juez justifica la elección de su interpretación, ya sea confirmando su inicial hipótesis interpretativa o eligiendo otra que fue develada en el transcurso del proceso de análisis. Esto nos sirve para entender que, en realidad, sí se puede descubrir cierta actividad cognitiva cuando el juez justifica su decisión en el documento público. De hecho, al respecto, Pino señala lo siguiente:

En efecto, en la justificación de la premisa normativa mayor del silogismo decisional, el juez muchas veces no se limita a enunciar la interpretación preseleccionada y los argumentos a su favor, sino que explícitamente repasa posibles objeciones y posibles alternativas (lo que, en parte, se debe a la propia estructura tríadica del proceso, que hace que el juez deba también tomar en cuenta los argumentos y los contraargumentos presentados por las partes). En estos casos, bastante frecuentes, parece que el límite entre el contexto de justificación y el contexto de descubrimiento se atenúa; que el primero "imita" al segundo (Pino, 2017, pp. 312-313). 
En segundo término, Pino hace referencia a la "fuerza civilizadora del contexto de justificación". Clásicamente se concibe que la justificación de la decisión judicial funciona como una garantía de las partes involucradas en el conflicto, así como un mecanismo de rendición de cuentas para la sociedad, en tanto implica el uso de poder que solo será legítimo si se encuentra justificado. Esta manera de aproximarse a la cuestión recuerda a las funciones endo y extraprocesales del deber de motivación propuestas por autores como Taruffo (Taruffo, 2006, pp. 309ss.; comentarios en Sotomayor, 2021a, pp. 23-31). El que los jueces justifiquen o motiven sus decisiones presupone que estos saben cómo hacerlo. Saber motivar puede entenderse aquí como saber justificar una decisión con razones obtenidas del derecho. Por una cuestión de formación, entonces, los jueces debieron aprender antes a razonar con reglas y justificar decisiones con las mismas. Es decir, el conocimiento de los rudimentos del razonamiento jurídico es una precondición básica de su capacidad para motivar.

Siguiendo esta línea de razonamiento, al analizar la decisión justificada de un juez puede descubrirse no solo las razones de la decisión, sino también que el juez sabe motivar y que, por tanto, obtuvo una adecuada formación (Pino, 2017, p. 314). Tal como recomienda Pino, este argumento debe manejarse con pinzas debido a su mera plausibilidad. De hecho, el argumento de Pino es en cierta medida problemático pues propone un cambio de perspectiva desde quien juzga hacia quien observa el acto de juzgar. En todo caso, mostraría que no solo para quien juzga es del todo clara la distinción entre CJ y CD, sino que este mismo problema de vaguedad afecta al observador del acto de juzgar.

Finalmente, Pino hace referencia a un tercer argumento, sobre "ideologías jurídicas". Con tal expresión Pino se refiere al esquema de trabajo que tiene todo juez. Asimismo, por esquema de trabajo puede entenderse todas aquellas técnicas interpretativas y de análisis, así como sus preferencias sobre estas, esquema con el cual enfoca los casos que conoce.

$\mathrm{Al}$ igual que en el segundo argumento, al concretizar la justificación en un documento público, este puede ayudar a descubrir el esquema de trabajo del juez, así como sus preferencias interpretativas para el caso solucionado. Pino advierte, nuevamente, que este argumento es meramente plausible, pero que puede ayudar a aclarar la razón por la que la distinción entre $\mathrm{CD}$ y $\mathrm{CJ}$ es menos tajante de lo que se imagina.

De lo dicho hasta este punto, puede entenderse que en el discurso jurídico se emplea la idea de contexto de descubrimiento en el sentido de descubrir, prima facie, las razones genuinas de la toma de decisiones por parte del juez. Consideramos, además, que ulteriormente se puede distinguir entre descubrir las razones genuinas de una decisión en un sentido fuerte o en sentido débil. 
El sentido fuerte, supondría el descubrimiento de las razones genuinas y evidenciadas de la decisión, acudiendo a los dos momentos del descubrimiento en la filosofía de la ciencia: la generación de una eventual hipótesis sobre las razones genuinas de la decisión en concreto, una investigación empírica y, finalmente, la justificación final de dicha hipótesis según las teorías existentes y aprobadas por la comunidad científica para darla por descubierta. Sería algo así como generar una teoría sobre las razones genuinas de la decisión $x$ aprobada por la comunidad científica. Se parte aquí de la premisa de que descubrir es un logro epistémico que permite identificar la existencia de algo, y que para que ese algo tenga existencia debe estar validado por las teorías existentes y la comunidad científica.

A diferencia del sentido fuerte, el sentido débil supondría la intuición de las razones genuinas de la decisión con el planteamiento de la hipótesis, una investigación lógica de la misma y su posterior justificación. Este proceso puede caracterizarse como el descubrimiento de algo sin necesidad de acudir a las reglas ni la aceptación de la comunidad científica. Bastaría, entonces, con el uso de herramientas lógicas interpersonales que permitan explicar las hipótesis. Su finalidad radicaría en explicar prima facie una hipótesis al margen de la aceptación científica.

Creemos, entonces, que para el caso del razonamiento jurídico, el sentido débil de descubrimiento resulta más relevante, debido al tiempo limitado y a las finalidades para las que es utilizado: justificar una decisión en el marco de las reglas de la lógica y las normas jurídicas.

\section{La lógica en el contexto de descubrimiento}

Como hemos desarrollado en la sección precedente, en la filosofía de la ciencia de la primera mitad del siglo XX existió una actitud reticente frente a la posibilidad de postular algo así como una "lógica del descubrimiento". Karl Popper es un buen representante de esta actitud $^{2}$, pues en una de las primeras secciones de La lógica de la investigación científica titulada "Eliminación del psicologismo" - señala que "La etapa inicial, el acto de concebir o inventar una teoría, no me parece que exija un análisis lógico ni sea susceptible de él. La cuestión acerca de cómo se le ocurre una idea nueva a una persona - ya sea un tema musical, un conflicto dramático o una teoría científica - puede ser de gran interés para la psicología empírica, pero carece de importancia para el análisis lógico del conocimiento científico" (Popper, 2017, pp. 37-38). Pensando en la actitud de Popper y otros filósofos de la ciencia, ante el proceso de descubrimiento de teorías, ideas y métodos, Fann (1970) concluye que “(...) estos filósofos ven al descubrimiento de nuevas ideas como una mera conjetura, azar, intuición, corazonada o algún salto mental por parte del científico, que solo

2 Citas equivalentes en la obra de otros filósofos de la ciencia se encuentran en Fann (1970, pp. 1-4). 
queda abierto para una investigación de tipo histórico, psicológico o sociológico. Cuando ellos hablan de la lógica del descubrimiento, solo se preocupan por la prueba de hipótesis" (p. 2, traducción propia). En suma, se niega la posibilidad de que la lógica del descubrimiento tenga una estructura racional equivalente a la que, por oposición, podríamos llamar lógica de la justificación de una teoría.

La sección precedente ha analizado de qué forma este tipo de formulaciones se relacionan con la distinción entre contexto de descubrimiento (CD) y contexto de justificación (CJ), desarrollada en el seno de la filosofía de la ciencia del empirismo lógico. Por ello, en esta sección nos concentraremos en responder una pregunta más concreta: ¿en qué sentido podemos hablar de una lógica del descubrimiento? Es decir, ¿en qué sentido empleamos aquí la palabra "lógica"? Por su parte, en la siguiente sección trataremos de responder a la pregunta sobre cómo opera dicha lógica, es decir, bajo qué esquema inferencial o argumentativo. Ambas preguntas serán abordadas priorizando los problemas jurídicos relacionados con el razonamiento probatorio.

Comencemos, entonces, con la pregunta de esta sección. Aunque no habría sido el primero -Gascón Abellán (2014, p. 152) menciona el tipo de inferencia aristotélica denominada "reducción" o "retroducción" como un antecedente-, se atribuye a Charles S. Peirce haber estudiado con cierto detalle la estructura de una forma de inferencia distinta a la deducción y a la inducción - aunque también de tipo ampliativo o sintético como la inducción- que llamó abducción (Walton, 2005, p. 3). A la vez, se le atribuye haber sostenido que la abducción es un tipo de inferencia que nos permite dar cuenta de la lógica de descubrimiento. No obstante, como reconocen especialistas en la obra del filósofo estadounidense, es en realidad bastante difícil reconstruir una suerte de teoría unitaria sobre la lógica del descubrimiento y sobre la abducción en la obra de Peirce. Ello, en buena medida, se debe al carácter fragmentario, caótico e incluso a veces contradictorio de la obra del autor pragmatista (Kraus, 2003, p. 237). En la medida que el presente artículo no propone una exégesis de la obra de Peirce, podemos evadir y dejar de lado esta compleja cuestión.

Sin embargo, un punto importante en la propuesta de Peirce es que en la postulación de un tipo de inferencia distinto a la deductiva e inductiva, encontramos una primera interpretación posible para la idea de una lógica del descubrimiento. En efecto, si, desde una perspectiva amplia, por "lógica" entendemos una disciplina dedicada a la reconstrucción y análisis de diversos tipos de inferencia, entonces la tarea a dilucidar en una lógica del descubrimiento consiste en (i) caracterizar el tipo de inferencia más común en lo que genéricamente podemos llamar actividades de descubrimiento, y (ii) analizar la estructura de tal tipo de inferencia, es decir, la forma de sus premisas y el tipo de conclusión a la que se arriba. 
Podríamos responder, entonces, señalando lo siguiente: la lógica de la justificación remite al tipo de inferencia que se emplea para justificar la conclusión de un razonamiento en el marco de una teoría científica, una sentencia judicial, entre otras formas de discurso. Estas inferencias pueden ser de tipo deductivo, en el que la conclusión se sigue necesariamente a partir de las premisas, siguiendo algún esquema válido de razonamiento; e, inductivo, en el que la conclusión se sigue - al menos en la llamada "inducción probabilística- con algún grado de probabilidad a partir de las premisas ${ }^{3}$. Por su parte, la lógica del descubrimiento remite al tipo de inferencia que se emplea para formular explicaciones o hipótesis que luego serán corroboradas. La forma básica de este tipo de inferencia puede seguir un esquema similar al inicialmente propuesto por Peirce y que será analizado con mayor detalle en la siguiente sección:

Se observa un hecho sorprendente E.

$\mathrm{Si} \mathrm{H}$ fuese verdadera explicaría que se haya producido E, por lo que E pasaría a ser algo ya no sorprendente.

Por lo tanto, hay razones para pensar que $\mathrm{H}$ es verdadera (formulación de Gascón Abellán, 2014, p. 152).

Un ejemplo, tomado del análisis que Giovanni Tuzet (2014, pp. 129-132) realiza de Los crímenes de la calle Morgue de E. A. Poe, puede ser de utilidad llegados a este punto.

Se observa el hecho sorprendente de que se ha encontrado, en un departamento de París, una escena impresionante: dos mujeres han sido asesinadas con ensañamiento, una de ellas estrangulada y luego su cuerpo clavado en la chimenea, mientras que la otra mujer ha sido decapitada. Asimismo, el hecho es sorprendente porque aparentemente no hay vías de escape del lugar y los testigos declaran haber escuchado la voz de alguien que parece ser un extranjero, aunque ninguno reconoce el idioma que esta hablaría.

Si la hipótesis de que una criatura no humana ha cometido el crimen (por ejemplo, un animal muy fuerte como un orangután) fuese verdadera, esta explicaría que se haya producido el hecho sorprendente, por lo que este ya no lo sería tanto.

Por lo tanto, hay razones para pensar que la hipótesis de la autoría de una criatura como un orangután es verdadera.

3 Recientemente, Tuzet menciona también al razonamiento analógico (2021, p. 129). Es importante apuntar que dicho tipo de razonamiento recibe un tratamiento amplio en la obra de autores de la tradición hermenéutica como Arthur Kaufmann (1999, cap. 5). 
En la formulación de Gascón Abellán, la lógica del descubrimiento atiende a la pregunta siguiente: ¿Por qué sucede este fenómeno? Mientras que corresponde a una fase hipotéticodeductiva la comprobación de las hipótesis postuladas.

Ahora bien, hasta este punto hemos seguido los pasos de la intuición de Peirce de que una lógica del descubrimiento podría consistir en el análisis de un tipo de inferencia, la abductiva, que difiere en sus rasgos distintivos, de las inferencias deductiva e inductiva. Pero esta no es la única alternativa para dotar de contenido a la idea de una "lógica del descubrimiento". Gascón Abellán postula que un segundo sentido en el que podemos hablar de una lógica del descubrimiento es entendiendo "lógica" como una suerte de metodología o racionalidad en la realización de un proceso o procedimiento. Este procedimiento se desarrolla en un arco temporal que nos lleva desde las hipótesis que se pueden sugerir a partir de pruebas primeras hasta la corroboración de tales hipótesis: "Podría decirse, por lo tanto, que el proceso de 'descubrimiento' de una hipótesis no es estrictamente independiente del proceso para su 'validación', pues ambos forman parte de una misma metodología inductiva" (Gascón Abellán, 2014, p. 157). Evidentemente no se trata de un procedimiento de tipo algorítmico, en el que el desarrollo de cada una de las fases cumple una suerte de protocolo estricto de instrucciones, sino de un procedimiento flexible en el que los elementos creativos se combinan con una fase de corroboración más parametrada.

Si entendemos "lógica" en este segundo y más flexible sentido, tenemos buenas razones para concluir que es posible postular una lógica del descubrimiento, entendida como un procedimiento ordenado que nos permite postular hipótesis que serán luego evaluadas. Más aún, si en el sentido más restringido de "lógica" buscamos un tipo de inferencia con una estructura típica, debemos concluir que la inferencia por antonomasia del proceso de descubrimiento es de tipo abductivo (aunque ello no impide que inducciones y deducciones estén presentes en el mismo procedimiento). Por tales razones, podemos concluir que (i) sí es posible hablar de una lógica del descubrimiento, y (ii) en qué consiste tal lógica dependerá de si adoptamos un sentido amplio de "lógica", o más bien uno más acotado: así, la lógica del descubrimiento podrá consistir en un procedimiento de formulación de hipótesis a partir de datos u observaciones iniciales (sentido amplio) o en un tipo de inferencia empleada típicamente para la postulación de hipótesis, tal como ocurre con la inferencia abductiva (sentido restringido). De esta forma, pues, damos respuesta a la pregunta sobre en qué sentido se puede hablar de una lógica del descubrimiento. En la siguiente sección, tomando el camino del sentido restringido, nos preguntamos por la estructura de la inferencia abductiva. 


\section{Modelos de razonamiento abductivo}

De acuerdo con Douven (2017a), a quien seguiremos de cerca en lo sucesivo, el término "abducción" se emplea, en la literatura filosófica, en dos sentidos distintos:

1. En un primer sentido de corte histórico, hace referencia al razonamiento explicativo en la generación de hipótesis.

2. En un sentido más contemporáneo, hace referencia al lugar del razonamiento explicativo en la justificación de hipótesis. En este segundo sentido, también se puede hablar de la "inferencia a la mejor explicación".

Sobre el primer sentido, Douven (2017b), sostiene que la teoría de la abducción de Peirce se ubica principalmente en el contexto de descubrimiento, es decir, en la fase de investigación en la cual buscamos generar teorías explicativas que serán posteriormente evaluadas. Peirce parece tener esto en mente cuando sostiene, por ejemplo, que la abducción remite al proceso de formación de hipótesis explicativas. La pregunta, entonces, es en qué sentido podemos decir que la abducción es una operación lógica. En Peirce ello se resuelve a través de un esquema de razonamiento sobre la abducción, que es el siguiente:

Un hecho sorprendente $C$ es observado.

Pero si A fuese verdad, C sería algo natural.

Entonces, hay una razón para sospechar que A es verdad.

Douven (2017b) nos recuerda que Harry Frankfurt (1958) desarrolla una crítica contra esta propuesta, y sostiene que aquí no hay una inferencia que conduzca a una nueva idea. Ello es así en la medida que la hipótesis explicativa A debe haber ocurrido antes de que uno infiera que esta es verdadera, pues ya aparece en la segunda premisa del esquema de Peirce. Por tal razón, Frankfurt se decanta por una segunda lectura de la abducción en Peirce, mediante la cual esta es un procedimiento no tanto para inventar una hipótesis para un hecho sorprendente, sino más bien para adoptar una hipótesis que lo explique. Aquí la abducción funcionaría como un filtro para determinar cuáles de las hipótesis sobre un hecho sorprendente pueden pasar a ser evaluadas en una siguiente fase.

El segundo sentido de "abducción" de los analizados por Douven (2017a) hace referencia al razonamiento explicativo desde el punto de vista de su estructura inferencial. Aquí la abducción se caracteriza como una de las tres más importantes formas de inferencia, siendo las otras la deducción y la inducción: mientras que la deducción es un tipo de inferencia en que la conclusión se sigue necesariamente de las premisas, esto no ocurre en la inducción y en la abducción. De esta forma, mientras que la deducción es analítica, la inducción y 
la abducción son sintéticas ( $v i d$. Niiniluoto, 2018, p. 8). Si bien ello permite diferenciar a la deducción de la inducción y la abducción, es todavía insuficiente para captar el rasgo distintivo de esta última frente a la inducción.

Una posible forma de diferenciar entre inducción y abducción consiste en sostener que en la abducción no solo ni principalmente se formula una conclusión basada en frecuencias estadísticas y probabilidades, sino que el centro se encuentra en una apelación a consideraciones explicativas ${ }^{4}$. Así, la hipótesis formulada explicaría coherentemente la colección de datos observados, y debido a ello se propone aceptarla.

Ahondemos en lo señalado en el párrafo precedente. A diferencia de la deducción, la abducción es un tipo de razonamiento no monotónico, en la medida que la adición o sustracción de premisas de un conjunto puede alterar la calidad de la explicación propuesta ${ }^{5}$. Pero es, además, un razonamiento que apunta hacia una explicación falible sobre un conjunto de datos. Por ejemplo, a partir de (a) la declaración de un testigo que señala haber visto a un hombre parecido a Manuel rondar la casa de Gonzalo minutos antes de la hora aproximada de la muerte (producida por puñaladas) de este, (b) de la lectura de varios correos electrónicos y mensajes de Whatsapp en los que Manuel amenaza a Gonzalo con hacerle daño y hasta matarlo, y (c) un video de seguridad que muestra que Manuel salió temprano de su oficina el día de la muerte de Gonzalo, el fiscal conjetura que la mejor hipótesis explicativa sobre quién pudo asesinar a Gonzalo es que lo hizo Manuel. De esta forma, piensa el fiscal, se contaría con un móvil - el odio de Manuel hacia Gonzalo-, así como con la posibilidad física de hacerlo - Manuel salió temprano del trabajo y pudo llegar a las inmediaciones de la casa de Gonzalo- y con una declaración que coloca a una persona que físicamente aparenta ser Manuel en las inmediaciones del lugar del crimen. Sin embargo, si a este conjunto de datos se agregara (d) una coartada por parte de Manuel —este, por ejemplo, se dirigió a casa de sus abuelos, donde permaneció hasta horas después de la hora de muerte de Gonzalo-, y esta fuese confirmada por declaraciones de testigos, o incluso por imágenes fotográficas o de video, la hipótesis original perdería gran parte de su poder explicativo. Con ello, podemos concluir que la incorporación de nuevas premisas en un razonamiento abductivo puede alterar la inferencia, ya no garantizando, en el caso de nuestro ejemplo, que Manuel es el probable autor del crimen.

\footnotetext{
4 En la misma línea, sostiene Tuzet (2021) que "En sentido estricto una inducción es una inferencia que generaliza datos; sus conclusiones no versan sobre casos particulares, sino sobre clases en su totalidad, mientras que las conclusiones del razonamiento probatorio [que para Tuzet es principalmente una inferencia a la mejor explicación de corte abductivo] en un contexto jurídico conciernen al caso particular de que se discute" (p. 133).

5 Desde luego, tanto la inducción como la abducción son tipos de razonamiento no monotónico. No obstante, lo que aquí resulta relevante es enfatizar la orientación explicativa de la abducción. En ese sentido, este trabajo no desarrolla una distinción refinada entre abducción e inducción, labor que se reserva para algún trabajo posterior.
} 
Douven (2017a) analiza algunas formulaciones esquemáticas de la abducción tomando en consideración algunas propuestas existentes en la literatura especializada. Una de estas versiones es la que llama "versión de libros de texto de la abducción" (textbook version of abduction), que tiene varias posibles formulaciones. Analicemos estas con mayor detalle:

Primera formulación: Dada la evidencia $\mathrm{E}$ y candidatas explicaciones $\mathrm{H}_{1}, \ldots, \mathrm{H}_{\mathrm{n}}$ para E, inferimos la verdad de aquella $\mathrm{H}_{\mathrm{i}}$ que mejor explique $\mathrm{E}$.

Esta primera versión exhibe, desde el punto de vista de Douven, varios problemas: en primer lugar, presupone los conceptos de "explicaciones candidatas" y de "mejor explicación". Para la noción de "mejor explicación”, se suele recurrir a virtudes de las teorías, tales como simplicidad, generalidad, coherencia y establecimiento de la teoría. Ahora bien, ninguna de estas virtudes posee una caracterización unánime en la literatura especializada, e incluso los críticos más extremos llegan a sostener que estas virtudes teóricas no tienen más que un rol retórico en la ciencia.

Un segundo problema de tal caracterización es que fuera de la vaguedad de los conceptos involucrados, esta podría ser demasiado fuerte: recordemos que la formulación habla de "la verdad" de una de las hipótesis. Hay quienes consideran que tal exigencia es muy elevada, y que puede ser reemplazada por expresiones como "probable verdad", "verdad aproximada", o una combinación de ambas.

Un tercer problema que considera Douven (2017a) es que en esta caracterización de la abducción, podríamos trabajar con un mal conjunto de explicaciones, siendo una de estas menos mala que las otras hipótesis propuestas. Ello es así pues solo se evalúa la relación entre la evidencia E y un conjunto de candidatas explicaciones. Para superar tal problema, y otorgar confiabilidad a la inferencia, deberíamos suponer que la hipótesis explicativa tiene el potencial de ser la mejor respecto de cualquier otro conjunto de hipótesis que podríamos haber concebido. No obstante, esta suposición parece ser, de acuerdo con los críticos, implausible, aunque hay intentos en el sentido de que se podría formular un universo finito de hipótesis que agoten el espacio lógico.

Finalmente, otra estrategia de crítica consiste en mostrar que la construcción de la primera formulación es asimétrica, en el sentido de que inicia con una premisa comparativa (sobre diversas hipótesis en pugna) y termina con una conclusión absoluta, que infiere la verdad de una de las hipótesis. Si ello es así, debemos evaluar otras alternativas.

Segunda formulación: Dada la evidencia E y candidatas explicaciones $\mathrm{H}_{1}, \ldots, \mathrm{H}_{\mathrm{n}}$ de $\mathrm{E}$, inferimos la verdad de aquella $\mathrm{H}_{\mathrm{i}}$ que mejor explique $\mathrm{E}$, siempre que $\mathrm{H}_{\mathrm{i}}$ sea una explicación, en tanto explicación, suficientemente satisfactoria/buena. 
Aquí, nuevamente, tenemos un problema de vaguedad, en la medida que se debe determinar qué cuenta como explicación satisfactoria/buena. No obstante, se logra salvar algunas de las críticas formuladas contra la primera versión, en la medida que un mal conjunto de explicaciones no contarán como explicaciones "suficientemente buenas o satisfactorias". No se logra salvar, sin embargo, la última de las críticas a la primera formulación, en la medida que se mantiene la falta de simetría entre premisas comparativas y una inferencia general de verdad. Ahora bien, esa crítica se ve matizada en la medida que la hipótesis explicativa en esta segunda formulación no solo es comparativamente la mejor del conjunto analizado, sino que es en sí misma buena/satisfactoria como explicación. De esta forma, la doble vertiente de exigencias (comparativas y sobre la calidad de la hipótesis) parece otorgar un mejor fundamento a la pretensión de verdad de la conclusión.

Finalmente, una tercera formulación se articula del siguiente modo:

Tercera formulación: Dada la evidencia E y candidatas explicaciones $\mathrm{H}_{1}, \ldots, \mathrm{H}_{\mathrm{n}}$ de $\mathrm{E}$, si $\mathrm{H}_{\mathrm{i}}$ explica $\mathrm{E}$ mejor que cualquiera de las otras hipótesis, inferimos que $\mathrm{H}_{\mathrm{i}}$ está más cerca de la verdad que cualquiera de las otras hipótesis.

Douven (2017a) considera que si bien aquí se mantiene el problema de definir que cuenta como "cercano a la verdad", la formulación posee la ventaja de que preserva la simetría entre premisa y conclusión de la inferencia. No obstante, un problema con esta tercera formulación es que la exigencia de que la hipótesis sea suficientemente buena o satisfactoria ha sido eliminada. Con ello, si bien se salva el problema de la falta de simetría entre premisa y conclusión, reingresa el problema de contar con un conjunto de hipótesis malas que son evaluadas.

Dados los inconvenientes que exhiben las tres opciones evaluadas por Douven (2017a), aquí proponemos una cuarta formulación, que, además, tiene una especial relevancia en el derecho y, en particular, en el razonamiento probatorio:

Propuesta de formulación: Dada la evidencia E, que en el razonamiento probatorio del derecho consiste en un conjunto de datos obtenidos a partir del análisis de medios probatorios; $y$ dadas las candidatas explicaciones $\mathrm{H}_{1}, \ldots, \mathrm{H}_{\mathrm{n}}$ para $\mathrm{E}$, si (i) $\mathrm{H}_{\mathrm{i}}$ explica $\mathrm{E}$ mejor que cualquiera de las otras hipótesis, y si (ii) $H_{i}$ es una explicación, en tanto que explicación, suficientemente satisfactoria/buena para $\mathrm{E}$, inferimos que $\mathrm{H}_{\mathrm{i}}$ está más cerca de la verdad que cualquiera de las otras hipótesis.

Evaluemos si esta propuesta sobrepasa las críticas formuladas por Douven contra la primera formulación, varias de las cuales se extendían a las otras alternativas analizadas por el autor mencionado. En primer término, nuestra propuesta mantiene el problema de cierta 
indeterminación en conceptos como "mejor explicación", "cercanía a la verdad", entre otros. Por ello, será menester tratar de clarificar tales conceptos para el caso del razonamiento probatorio, que es el centro del análisis aquí. No obstante, en nuestra propuesta se salva el segundo problema, pues no se infiere la verdad de la hipótesis sino la "mayor cercanía la verdad". Por ello, nuestra propuesta no es tan fuerte como la primera. Asimismo, se salva la crítica del posible conjunto de malas explicaciones, en la medida que nuestra propuesta recurre a dos criterios: comparativo (entre $\mathrm{H}_{\mathrm{i}}$ y las otras candidatas explicaciones) y sobre la calidad de la hipótesis, por lo cual la $\mathrm{H}_{\mathrm{i}}$ debe ser, en sí misma, una explicación suficientemente satisfactoria para E. Una estrategia análoga se encuentra, por ejemplo, en las dos condiciones que componen la propuesta de un estándar de prueba para el proceso penal (el estándar de más allá de toda duda razonable) propuestas por Ferrer Beltrán (2007, p. 147).

Entonces, el concepto de suficiencia puede corresponderse, para el razonamiento probatorio, con la noción de estándar de prueba, pero esto es algo que queda por desarrollar en nuevas investigaciones.

Finalmente, nuestra propuesta salva el problema de la falta de simetría entre premisa y conclusión, en la medida que la premisa es comparativa y la conclusión no es absoluta sino altamente plausible (por ello está definida en términos de cercanía a la verdad). Si el intento emprendido hasta este punto es exitoso, hemos logrado ofrecer una caracterización de la estructura de la inferencia abductiva que la diferencia de otras inferencias como la deductiva o la inductiva. Queda, entonces, por analizar cómo la abducción se materializa en el análisis de casos relacionados con el razonamiento probatorio.

\section{La práctica de la abducción en el razonamiento probatorio jurídico}

De acuerdo a Bonorino (2014) “(...) uno de los problemas al que nos enfrentamos quienes tratamos el tema del razonamiento abductivo es el poder ofrecer un ejemplo claro y reconocible de abducción" (p. 163). Sin embargo, ello no es impedimento para asumir el reto de dicha empresa y ofrecer dos ejemplos reales y recientes ${ }^{6}$ de cómo la abducción, primero, nos permite dotar de racionalidad al contexto de descubrimiento y, segundo, cómo el análisis de casos en concreto, en el marco de un análisis abductivo, nos permite elaborar un diseño institucional para acercarnos a la verdad, según expusimos en las secciones precedentes.

Esta empresa, además, resulta necesaria para disipar y superar la brecha que suele existir entre la teoría, los diseños intelectuales y la práctica jurisprudencial de los juzgados en el

6 Ambos casos fueron resueltos por la Sala Penal Permanente de la Corte Suprema de Justicia de la República del Perú, y están disponibles en la página web del Poder Judicial (www.pj.gob.pe), en los ítems de “Consulta de expedientes judiciales - Supremo" y “Jurisprudencia”. También están disponibles en otras páginas web, como www. gacetajuridica.com.pe o www.lpderecho.pe. 
derecho, y así evitar que existan dos mundos paralelos de teoría y práctica. El objetivo, entonces, es que ambos ámbitos puedan colaborar de forma fructífera.

\section{Un primer caso: Recurso de Nulidad N. ${ }^{\circ} 2098-2019$ Lima $^{7}$}

El 4 de julio de 2018, la policía intervino y detuvo a Nilso Lerma, de nacionalidad colombiana, cerca del local de la empresa de transportes Flores Hermanos, ubicada en el distrito de La Victoria, Lima. Días antes, Nilso Lerma había enviado una encomienda desde la ciudad de Lima hacia Puno, y luego había viajado hacia esta última ciudad. Sin embargo, no logró tal cometido y solo llegó hasta Arequipa, ciudad que está en camino hacia Puno. Luego de este viaje trunco regresó a Lima a recoger la encomienda que había enviado antes. La detención de Lerma se debió a que actuaba de forma sospechosa y pretendía recoger la encomienda previamente enviada. Al realizarse el registro del bien enviado, se encontraron dos cilindros de pintura que tenían compartimientos acondicionados, y al interior de estos se hallaron 29 paquetes donde existían restos de vegetales, tallos y semillas, similares a la marihuana.

Ante estos primeros hallazgos, se realizaron las siguientes diligencias: (i) se redactó un acta de registro personal e incautación, donde se dejó constancia de la encomienda y los bienes hallados en poder del intervenido: tres celulares, la boleta de envío de la encomienda y "nada de dinero" (sic); (ii) la sustancia encontrada fue sometida a los exámenes químicos y de pesaje correspondientes, y se determinó que era marihuana, con un peso bruto de 27,945 kilogramos; y, (iii) se recibió la declaración del intervenido, quien señaló que el 19 de junio de 2018 llegó a la ciudad de Piura, proveniente desde Colombia, y fue allí que casualmente conoció a Ítalo Madrid, quien durante varios días lo ayudó a conocer esta ciudad, le hizo diversos favores, lo atendió amablemente y le pidió el favor de que lo ayude a enviar una encomienda de pintura de Lima a Puno. De acuerdo con la narración de Lerma, Ítalo Madrid no podía realizar el envío porque extravió su documento de identidad. Nilso Lerma accedió al pedido, de acuerdo a su versión de los hechos, a pedido de Madrid, y debido a la amabilidad y la gran hospitalidad con la que fue atendido. Lerma también indicó que no conocía el contenido ilícito de la encomienda que envió ni participó en su acondicionamiento, y que vino al Perú a conocer los restos arqueológicos de Machu Picchu. Asimismo, precisó

7 En el ordenamiento jurídico peruano coexisten dos normas procesales bajo cuyas reglas se siguen los procesos penales: el Código de Procedimientos Penales (derogado, pero que aún se aplica en los casos penales ocurridos con anterioridad al 2004) y el Código Procesal Penal de 2004 (de vigencia progresiva en todo el país). El recurso extraordinario que permite llegar a la Corte Suprema de Justicia, para el caso del Código de Procedimientos Penales, es el Recurso de Nulidad (los casos evaluados poseen tal condición). Por su parte, en el caso del Código Procesal Penal, es el Recurso de Casación. Más allá de los matices propios de cada norma procesal, en ambos casos la Corte Suprema conoce todos los casos elevados a dicha instancia, las cuales son numerados según el orden de ingreso a dicha instancia, seguido del nombre de la Corte Superior de Justicia de donde proviene el caso. 
que el personal de la empresa de transportes, días después de haber enviado la encomienda y cuando se encontraba en Arequipa, se comunicó con él y le dijo que del paquete estaba goteando un líquido, por lo que tenía que recogerlo, y fue al realizar esta acción que fue detenido por la policía. Finalmente, añadió que consignó su propio nombre como destinatario de la encomienda enviada.

A partir de lo descrito hasta aquí, tenemos los siguientes "datos probatorios disponibles" (D):

- D1: Nilso Lerma e Ítalo Madrid Riofrío aparentemente se conocieron en Piura; además, este le hizo muchos favores y lo atendió amablemente en dicha ciudad.

- D2: Nilso Lerma envió una encomienda de Lima a Puno.

- D3: Dicha encomienda tenía camuflados 27,945 kilogramos de marihuana.

- D4: Nilso Lerma indicó que desconocía del contenido ilícito de la encomienda y precisó que estaba viajando a Cusco, a conocer Machu Picchu.

- D5: Días después de haber realizado el envío de la encomienda, Lerma regresó a la empresa de transportes, a recoger el bien enviado, debido a que le informaron que el mismo estaba goteando. No se encontró en su poder suma dineraria alguna.

- D6: Solo se intervino a Nilso Lerma cuando este se acercó a recoger la encomienda, y se advirtió que el envío tenía como destinatario al mismo remitente.

A partir de los datos probatorios descritos, se advierte que estamos ante un caso misterioso: de un lado, el intervenido envió una encomienda que tenía camuflada una cantidad considerable de marihuana y, de otro, indicó que hizo ello como agradecimiento por la hospitalidad y los muchos favores que un ciudadano peruano - que casualmente conoció en Piura- le realizó. Pero también señaló que desconocía del contenido ilícito del envío (creía que era pintura) y añadió que tampoco participó en el acondicionamiento de la droga.

¿Por qué creer que una persona que viajaba a Machu Picchu, de ser cierto ello, haya enviado una encomienda con marihuana a Puno?, ¿será cierto que hizo ello como agradecimiento por la hospitalidad que recibió en Piura?, ¿es razonable actuar de esa forma?, ¿había alguna forma de conocer del contenido ilícito del envío?, ¿habrá participado en su acondicionamiento?, ¿qué habría hecho usted o una persona razonable en similares circunstancias? Estas interrogantes, entre otras muchas que podrían surgir, hacen que el caso sea uno misterioso (además de ser bastante común en los tribunales peruanos). 


\section{a. Las posibles hipótesis sobre lo ocurrido}

A partir de los "datos probatorios disponibles" podemos formular las siguientes "hipótesis explicativas"8 $(\mathrm{H})$ sobre lo acontecido:

- H1: Nilso Lerma (NL), con la asistencia de Ítalo Madrid, envió, desde Lima a Puno, una encomienda que tenía camuflada marihuana y conocía del contenido ilícito del envío. Respaldan esta afirmación el hecho de que envió una encomienda (D2) que tenía camuflados 27,945 kilogramos de marihuana (D3) y, días después, regresó a recogerla a Lima (D5).

- H2: NL envió a Puno una encomienda (D2) que tenía camuflada marihuana (D3), pero no conocía de su contenido ilícito (D4), pues realizó el envío en gratitud por la hospitalidad y los favores que le hizo Ítalo Madrid (D1).

- H3: NL envió la encomienda (D2) que tenía camuflada una cantidad considerable de marihuana (D3), sin que haya intervenido en ello Ítalo Madrid $\mathrm{u}$ otra persona, pues la policía solo intervino al primero (NL); además, al momento de realizar el envío, consignó como destinatario de la encomienda su propio nombre (D6).

De todas estas hipótesis podemos excluir a la tercera (H3), pues consideramos que el investigado debió requerir la asistencia de terceras personas para adquirir la sustancia ilícita en el Perú, camuflarla en los cilindros de pintura, obtener dinero para realizar todos los actos preparatorios del traslado y envío de la encomienda y, después, ejecutado propiamente dicha actuación (envío). Estas razones debilitan la tercera hipótesis. Además, tampoco existen mayores "datos probatorios disponibles" que doten de mayor credibilidad a tal hipótesis.

Asimismo, podemos afirmar que existen suficientes razones y "datos probatorios disponibles" que dotan de credibilidad a las dos primeras hipótesis explicativas (H1 y H2), debido a que, de un lado, Nilso Lerma realizó el envío de una encomienda donde se camufló una cantidad considerable de marihuana y después fue a recogerla; y de otro, se presume su inocencia, por tanto, también debe considerarse su versión de los hechos. De modo que estas dos hipótesis resultan sostenibles.

\section{b. Actuaciones a realizar para resolver el caso}

\footnotetext{
8 Seguramente podrían formularse más hipótesis; sin embargo, únicamente con el fin de presentar un caso de la forma más clara posible, no haremos mayores proposiciones hipotéticas que podrían complicar o hacer más tediosa la lectura y el entendimiento del caso y, por tanto, del ejemplo propuesto.
} 
A partir de los "datos probatorios disponibles" y las "hipótesis sostenibles advertidas", resulta claro que se necesita la producción de nuevos elementos que permitan determinar la verdad de lo ocurrido. Entre dichas actuaciones tenemos las siguientes:

- A1: Ver los mensajes de texto que envió y recibió NL días antes de la remisión de los bienes ilícitos y su intervención. De la lectura de estos mensajes se advirtió que el intervenido se comunicó con Ítalo Madrid y allí coordinaron sobre cuestiones tales como (i) el traslado de la encomienda donde se escondió la marihuana, desde Piura hacia Lima; (ii) su envió desde Lima hacia Puno y (iii) los 500 dólares que le pagarían por realizar dicha labor ilícita. De estas conversaciones también se advirtió que (vi) Lerma viajó a Arequipa y allí intentó recoger la encomienda, pero que ello no se concretó porque la encomienda se quedó en Lima, y, (v) ante la llamada de los representantes de la empresa de transportes, Lerma regresó a Lima, manifestando a Ítalo Madrid que tenía miedo de que hayan descubierto la droga o le estén tendiendo una trampa para detenerlo. Finalmente, se advirtió que (vi) Ítalo Madrid le dijo que por seguridad borre las conversaciones que mantuvieron.

- A2: Recibir las declaraciones de los policías que intervinieron a NL. Los efectivos policiales Cali Lima y Anderson Carrasco indicaron que por información de inteligencia tomaron conocimiento del envío de una encomienda con marihuana camuflada, por lo que intervinieron a Nilso Lerma y, en el envoltorio que envió a Puno, se encontraron 29 paquetes de marihuana.

- A3: Recibir las declaraciones de los representantes de la empresa de transportes Flores Hermanos. Yony Ordoño indicó que participó en la intervención de Nilso Lerma y detalló que en la encomienda se encontró marihuana. Por su parte, Julisa Huamán señaló que recibió la encomienda, que NL no se quiso identificar y solo ante su insistencia entregó su carnet de identidad colombiana; también dijo que el investigado le indicó que el paquete enviado contenía herramientas.

- A4: Recabar las grabaciones de seguridad del momento de envío de la encomienda donde se camufló la marihuana. De la revisión de estas imágenes se advierte que los relatos brindados por Yony Ordoño y Julisa Huamán son veraces. 
- A5: Identificar a Ítalo Madrid Riofrío y recibir su declaración. Esta persona aceptó su responsabilidad, pero no otorgó información adicional sobre lo ocurrido.

\section{c. Evaluación definitiva de las hipótesis}

Del análisis de los nuevos elementos actuados no resulta posible proponer nuevas hipótesis explicativas del caso. Por ello, ahora debe identificarse cuál es la "mejor explicación del caso", partiendo de las alternativas existentes. Para ello se analizará qué elementos confirman o rechazan alguna de las dos "hipótesis sostenibles", es decir, se evaluará los puntos fuertes y débiles de ambas hipótesis.

Con relación a la primera hipótesis (H1) advertimos que esta cuenta con puntos sólidos, pues NL envió una encomienda de Lima a Puno (D2), que contenía 27,945 kilogramos de marihuana (D3), que estaban camuflados en el interior de dos cilindros de pintura. Además, días después de haber realizado el envío de la encomienda regresó a la empresa de transportes a recoger el bien enviado (D5). Esto, a su vez, es respaldado con los mensajes de texto y las conversaciones por mensajes de texto que mantuvo NL (A1) con el otro responsable del delito, las declaraciones de los policías Cali Lima y Anderson Carrasco (A2), los relatos de Yony Ordoño y Julisa Huamán (A3) y la visualización de los videos de seguridad de la empresa de transportes (A4). No encontramos puntos débiles en esta hipótesis.

Respecto a la segunda hipótesis (H2) advertimos puntos fuertes y puntos débiles. Sobre los primeros, NL e Ítalo Madrid aparentemente se conocieron en Piura (D1), aun cuando ello no fue corroborado, y solo se intervino a NL cuando pretendía recoger la encomienda (D6). Sin embargo, estos datos iniciales adolecen de muchos puntos débiles, pues Ítalo Madrid no otorgó información alguna sobre lo ocurrido (A5) y se limitó a aceptar su responsabilidad; tampoco se encontró en posesión del intervenido dinero alguno o bienes suficientes para que puedan hacer presumir su viaje a Machu Picchu (D5). Este análisis nos permite concluir que la segunda hipótesis (H2) presenta importantes puntos débiles que hacen posible su exclusión.

De modo que, después de haber pasado de las pruebas a las hipótesis (narración de hechos, análisis de datos, formulación de todas las hipótesis y selección de las que resulten posibles, donde se hizo una indagación necesaria, la reconstrucción de los hechos con hipótesis decisivas y el establecimiento de las direcciones de la investigación) y, luego, de las hipótesis a las pruebas (análisis decisivo de las hipótesis planteadas, a partir de los nuevos elementos producidos, y la verificación de las mismas - confirmación o rechazo de las hipótesis con las pruebas decisivas, a partir de su análisis de puntos fuertes y débiles-) 
podemos concluir que la mejor explicación del caso o la hipótesis que mejor explica el caso (definitiva) es H1, esto es, que NL envió, desde Lima hacia Puno, una encomienda que tenía camuflada marihuana y conocía del contenido ilícito del envío?.

Todo el análisis precedente puede graficarse de la siguiente manera:

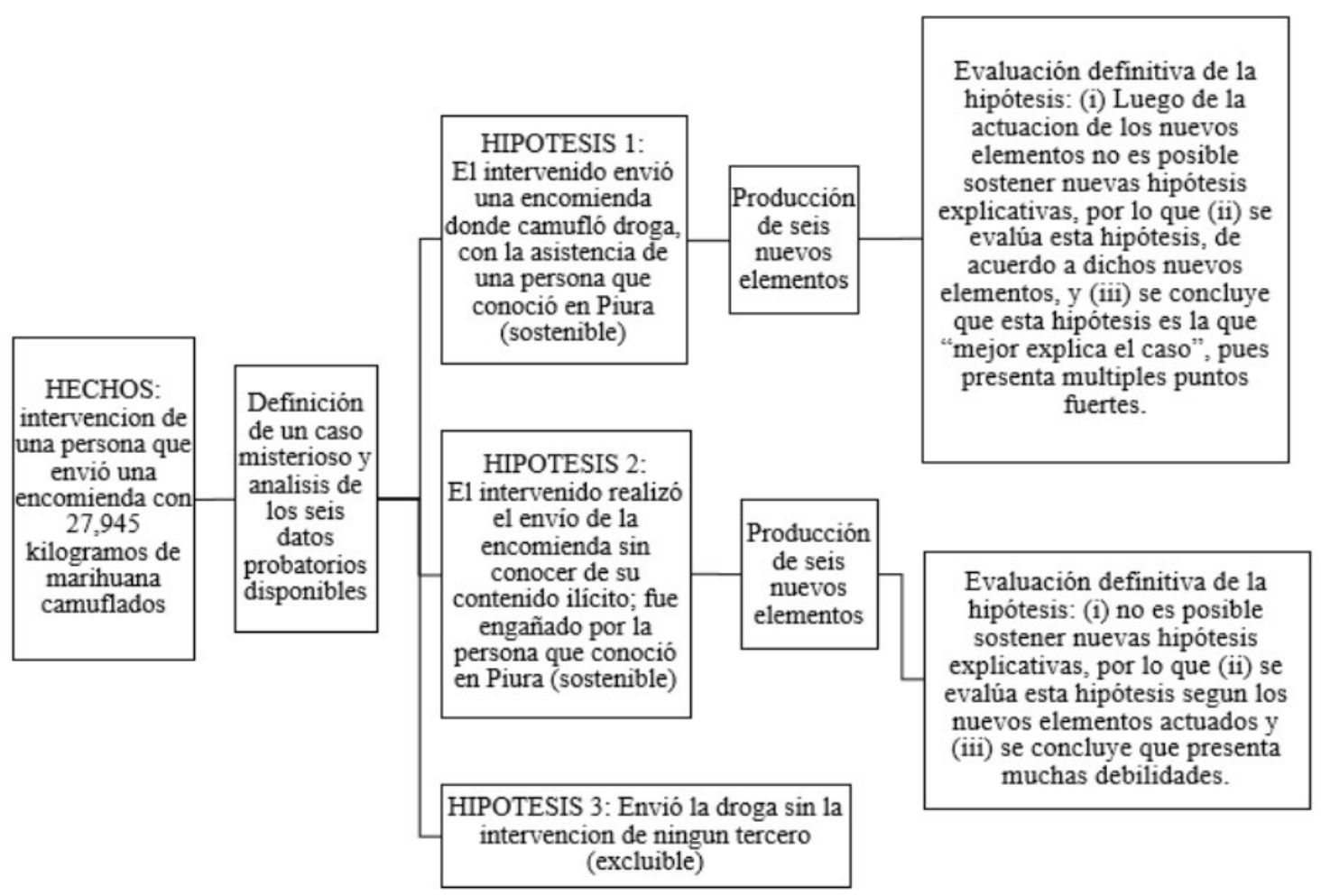

Gráfico 2: Síntesis del análisis del Recurso de Nulidad N. ${ }^{\circ} 2098-2019$ Lima

Fuente: elaboración propia.

El análisis del caso descrito, que fue recientemente resuelto por la Corte Suprema de Justicia, nos permite dotar de relevancia práctica a los argumentos expuestos en las secciones precedentes, y así defender la tesis de que la incorporación de un análisis sobre la abducción nos lleva hacia una teoría de la argumentación jurídica centrada no solo en el contexto de justificación, sino también en el contexto de descubrimiento, esto es, hacia una compleja teoría sobre la racionalidad en el análisis y la toma de decisiones, capaz de incorporar la racionalidad del proceso de descubrimiento (en la misma línea véase Sotomayor, 2021b, pp. 107-128).

9 Esta también fue la conclusión de la Corte Suprema de Justicia, que condenó a Nilso Lerma como autor del delito de tráfico ilícito de drogas, en perjuicio del Estado peruano. 
Ahora bien, nuestro análisis no concluye aquí, pues a continuación pasaremos revista a un segundo caso, siguiendo el mismo esquema descrito, pero esta vez avanzaremos un poco más: a partir de un análisis abductivo, primero introduciremos una nueva hipótesis (después de la actuación de nuevos elementos) y, luego, intentaremos elaborar un diseño institucional que nos permita llegar a la verdad del caso (a futuro).

\section{Un segundo caso: Recurso de Nulidad N. ${ }^{\circ} 1562-2019$ Selva Central}

La menor de iniciales G. M. G. quedó embarazada a los 12 años de edad. Ello motivó que Iván Villaizan, que era su pareja sentimental, sea detenido, pues la menor jurídicamente no podía consentir ningún acto sexual ${ }^{10}$. Esta persona, al ser detenida, indicó que no mantuvo relaciones sexuales con la menor embarazada y que esta, cuando tenía 11 años, convivió y practicó actos sexuales con Fray Huacho, en la vivienda donde residía -la menor- con su hermana y abuela, aprovechando que aquel -Fray Huacho- laboraba en una obra de construcción cercana.

Ante estas primeras declaraciones, se realizaron las siguientes diligencias: (i) se recibió la declaración de la menor, quien señaló que antes de mantener relaciones sexuales con Iván Villaizan, que era su conviviente y el padre del niño que esperaba, convivió y mantuvo relaciones sexuales con Fray Huacho, y añadió que el abogado Percy Coronado le pidió que niegue haber mantenido relaciones sexuales con Iván Villaizan, para que esta persona sea liberada; (ii) se recibió la declaración de Avelina García, madre de la menor, quien genéricamente indicó que su hija convivió con Fray Huacho; (iii) se practicó un examen médico legal a la menor, el cual concluyó que tenía 18 semanas de embarazo y presentaba signos de "desfloración antigua"; y, (iv) se practicó un informe social donde se indicó que dos de las tías de la menor señalaron que su sobrina convivió y mantuvo relaciones sexuales con Fray Huacho.

A partir de lo descrito, tenemos los siguientes "datos probatorios disponibles" (D):

- D1: La menor vivía con su hermana y su abuela (no con su madre), y a los 12 años quedó embarazada.

- D2: Ella indicó que convivió, respectivamente, con Fray Huacho e Iván Villaizan, y que este último era el padre del niño que esperaba.

- D3: G. M. G. añadió que el abogado Percy Coronado le pidió que mienta, para que Iván Villaizan (patrocinado del abogado y, a la vez, pareja de la menor) sea liberado.

10 Es importante precisar que aquí no realizaremos un análisis y evaluación desde una perspectiva o enfoque de género, con el único fin de que podamos reconstruir el problema de la forma más fidedigna posible respecto de lo resuelto por la Sala Penal Permanente de la Corte Suprema de Justicia de la República. 
- D4: Avelina García e Iván Villaizan indicaron que la menor convivió con Fray Huacho, en la casa donde aquella -a menor- vivía con su hermana y su abuela, antes de quedar embarazada. A similar conclusión arribó el informe social actuado.

A partir de los datos probatorios descritos, se advierte que estamos ante un caso complejo: de un lado, una menor de 12 años quedó embaraza y, de otro, no se sabe con quién mantuvo relaciones sexuales, a pesar de que jurídicamente no tenía libertad para consentir ello (ni quién es el padre del niño que espera). Su madre y su pareja sentimental indican que convivió con Fray Huacho, niegan la paternidad de Iván Villaizan y el abogado Percy Coronado aparentemente indujo a la menor a que mienta para que su patrocinado sea liberado. Asimismo, no se recibió la declaración de Fray Huacho, debido a que no se le pudo ubicar en la localidad donde ocurrieron los hechos. ¿Qué habrá ocurrido en verdad?

\section{a. Las posibles hipótesis sobre lo ocurrido}

A partir de los "datos probatorios disponibles", podemos formular las siguientes "hipótesis explicativas" $(\mathrm{H})$ de lo acontecido:

- H1: La menor convivió (D4) y fue agredida sexualmente por Fray Huacho (D2).

- H2: La menor convivió (D4), fue agredida sexualmente por Fray Huacho (D2) y quedó embarazada de esta persona (D1).

- H3: La menor convivió (D4), fue agredida sexualmente por Iván Villaizan (D2) y quedó embarazada de esta persona (D1), pero su abogado le dijo a la menor que mienta, para que su pareja sea liberada.

- H4: La menor convivió (D4) y fue agredida sexualmente por Fray Huacho (D4) e Iván Villaizan (D2), es decir, por ambas personas.

De estas hipótesis explicativas, podemos excluir a H2 (la menor no dijo que el padre del niño que esperaba fuese Fray Huacho, por lo que esta hipótesis no cuenta con datos probatorios que la amparen ${ }^{11}$ ) y $\mathbf{H} 4$ (las hipótesis H1 y $\mathbf{H 3}$ engloban mejor a esta hipótesis), debido a que presentan mínimos datos probatorios a su favor y varios datos en su contra ${ }^{12}$,

\footnotetext{
11 Es importante no perder de vista que en esta etapa del análisis solamente contamos con datos probatorios obtenidos de las declaraciones de la menor y su madre, así como un examen médico legal a la menor, y un informe social.

12 Quizás alguna de estas hipótesis también podrían resultar sostenibles, en mayor o menor medida, según los datos
} 
a diferencia de $\mathbf{H 1}$ y $\mathbf{H 3}$, sobre las cuales únicamente existen datos probatorios que las respaldan y, a su vez, las dotan de mayor credibilidad. De modo que estas dos últimas hipótesis resultan sostenibles.

\section{b. Actuaciones a realizar para resolver el caso}

A partir de los "datos probatorios disponibles" y de las "hipótesis sostenibles" advertidas, es necesaria la "producción de nuevos elementos" que permitan determinar la verdad de lo posiblemente ocurrido. Entre dichas actuaciones tenemos:

- A1: Recibir la declaración de la menor, a efectos de que ofrezca mayores detalles sobre lo que, de forma genérica, había señalado antes. Esta declaración busca establecer con quién mantuvo relaciones sexuales y convivió, quién es el padre de su hijo y cuál fue la participación del abogado Percy Coronado en su inicial declaración. Así, se recibieron dos declaraciones de la menor, donde reiteradamente señaló lo siguiente:

- Vivía con su abuela y su hermana, no con su madre.

- No brindó detalle alguno sobre su presunta convivencia o realización de actos sexuales con Fray Huacho, porque ello nunca ocurrió.

- Sindicó a Fray Huacho para que liberen a Iván Villaizan, que era su conviviente y el padre del niño que esperaba, por recomendación del abogado Percy Coronado, quien le dijo que no pasaría nada si mentía, pues no podrían identificar o detener a Fray Huacho, ya que no sabían dónde estaba. Así, con la declaración falsa, lograría que se libere a su pareja.

- Tanto Iván Villaizan como los miembros de su familia presionaron a G. M. G. para que mienta, pues le decían que por su culpa se detuvo a su conviviente y que su hijo se quedaría sin padre.

- Conoció de vista a Fray Huacho debido a que su abuela le vendía comida en una obra, más nunca tuvo relación sentimental o amical alguna con esta persona. Más aún, G. M. G. señaló que, debido a su

probatorios disponibles que consideremos pertinentes; incluso podría existir una quinta hipótesis lotra persona, no identificada, agredió sexualmente a la menor y es el padre del niño que espera); sin embargo, nuevamente con el fin de presentar un caso de la forma más clara y concreta posible, no haremos mayores formulaciones que podrían complicar o hacer más tediosa la lectura y el entendimiento del caso y, por tanto, del ejemplo propuesto. 
inmadurez, trataba despectivamente a Fray Huacho, quien le parecía una persona de la sierra que "no se arreglaba físicamente".

- Cuando quiso decir la verdad, Iván Villaizan se la llevó a otro lugar.

- Cuando quedó embarazada convivía con Iván Villaizan y la familia de esta persona, quienes la presionaban y coaccionan para que no diga la verdad y así se evite perjudicar a su conviviente y real agresor, con quien tuvo relaciones sexuales a los 11 años.

- No tuvo ninguna comunicación, contacto o cercanía con Fray Huacho, antes o después de quedar embarazada; tampoco tenía vínculo de dependencia economía, afectiva o familiar con esta persona.

- A2: Recibir la declaración de la hermana y la abuela de la menor, debido a que al momento de ocurridos los hechos G. M. G. vivía con ellas.

- Ernestina Chumbes (la abuela) señaló que vendía comida a Fray Huacho en una obra donde esta persona trabajaba, pero que no tenía mayor cercanía con dicha persona. También indicó que la menor es su nieta, vivía con ella y que esta nunca convivió con Fray Huacho. Asimismo, precisó que el enamorado de la menor era Iván Villaizan y que el abogado Percy Coronado fue quien indujo a mentir a la menor, de forma tal que se libere a Iván Villaizan.

- Yesenia Miranda (la hermana) indicó que vivía con la menor G. M. G. y su abuela. También señaló que Fray Huacho jamás vivió con su hermana y que ella dijo eso para que liberen a Iván Villaizan y todo fue organizado por el abogado Percy Coronado. Además, precisó que cuando la menor quiso decir la verdad, Iván Villaizan se la llevó de la casa.

- Ambas personas también señalaron que no tuvieron comunicación, contacto o cercanía alguna con Fray Huacho y precisaron que esta persona estuvo en el pueblo por un periodo corto, en que laboró en una obra de construcción, y después se fue, sin que lo hayan vuelto a ver.

- A3: Recibir la declaración de Fray Huacho. Esta persona negó cualquier amistad, cercanía, convivencia o realización de algún acto sexual con la menor. Asimismo, indicó que vivía en otro lugar y que nunca tuvo contacto con la menor, a quien solo conocía porque su abuela le vendía comida en 
la obra donde él trabajaba, pero una vez que concluyó esta actividad se regresó a su ciudad de origen, sin saber nada de lo supuestamente ocurrido.

\section{c. Evaluación definitiva de las hipótesis}

Del análisis de los nuevos elementos actuados resulta posible sostener una nueva hipótesis explicativa del caso (nótese que esto no ocurría en el primer ejemplo que analizamos). La nueva hipótesis es que la menor se retractó para eximir de responsabilidad a Fray Huacho (H5). Por ello, debe identificarse cuál de las tres hipótesis sostenibles (las dos iniciales o esta nueva) es la que "mejor explica el caso". Para ello se analizará qué elementos confirman o rechazan las "hipótesis sostenibles". Además, con un fin estrictamente metodológico, primero se analizará la nueva hipótesis y, después, se evaluará las otras dos hipótesis sostenibles.

Con relación a la nueva hipótesis explicativa (H5) advertimos que esta presenta múltiples puntos débiles, por lo siguiente:

- Avelína García (madre de la menor) indicó que su hija convivió con Fray Huacho. Sin embargo, la menor no vivía con su madre, pues estaba al cuidado de su hermana y su abuela. Ello resta veracidad al relato de Avelína García. Además, las dos tías de la menor no ratificaron sus presuntos relatos (los que sustentaron el informe social). La menor, en su primer relato, tampoco brindó detalles de su presunta convivencia con Fray Huacho o sobre los actos sexuales que mantuvo con este (su relato fue genérico). Asimismo, el nombre de Fray Huacho apareció solo después de que Iván Villaizan (conviviente de la menor) fue detenido y cuando la menor estaba embarazada. Ello nos permite concluir, luego de analizar la solidez o debilidad del inicial relato de la menor, que su incriminación inicial es débil (conclusión parcial 1).

- La menor reiteradamente indicó que no convivió ni mantuvo relaciones sexuales con Fray Huacho y que dijo eso para que liberen a Iván Villaizan, que era su conviviente y el padre del niño que esperaba, todo por recomendación del abogado Percy Coronado, quien le dijo que no pasaría nada si narraba dicha versión, y que con ello lograría que liberen a su pareja. Añadió que Iván Villaizan y toda la familia de esta persona la presionaron para que mienta, pues le decían que por su culpa se detuvo a su conviviente. También precisó que conoció de vista a Fray Huacho porque su abuela le vendía comida en una obra de construcción, pero ella nunca tuvo alguna 
relación sentimental o amical con él, e incluso añadió que por su inmadurez trataba despectivamente a esta persona. Este relato es corroborado por la declaración de Ernestina Chumbes, abuela de la menor, quien indicó que su nieta vivía con ella y nunca convivió con Fray Huacho; además, precisó que el enamorado de la menor era Iván Villaizan y que el abogado Percy Coronado fue quien pidió a G. M. G. que mienta para que así suelten al padre de su nieto. Por su parte, Yesenia Miranda, hermana de la menor, indicó que vivía con la agraviada y que Fray Huacho jamás vivió con su hermana. También indicó que la menor dijo eso para que liberen a Iván Villaizan y que todo fue organizado por el abogado Percy Coronado. Además, precisó que cuando G. M. G. quiso decir la verdad, Iván Villaizan se la llevó a otro lugar y no supieron nada de ella. Esto nos permite concluir que existe coherencia interna y exhaustividad en el nuevo relato (retractación), el que también cuenta con capacidad corroborativa (conclusión parcial 2).

- La menor reiteramente señaló que cuando quedó embarazada convivía con Iván Villaizan y la familia de esta persona. Esto hace que sea razonable pensar que en dichas condiciones haya mentido para que se libere a su pareja sentimental. Sería con tal finalidad que la menor habría sindicado falsamente a Fray Huacho, que era una persona que casualmente trabajó en el lugar. Además, es razonable pensar que cuando haya querido decir la verdad, la familia de su pareja la haya presionado o coaccionado para que no perjudique a su conviviente y real agresor, pues vivía con estas personas, y para todo ello contó con la asistencia del abogado Percy Coronado, que defendía a su pareja. Evidentemente dichas conjeturas se sostienen en máximas de la experiencia que podrían ser analizadas críticamente con mayor detalle, pero que para los fines de nuestro argumento basta con sostener que son plausibles. Todo lo hasta aquí mencionado hace razonable la tesis de que la menor brindó una inicial información falsa, que resulta proporcional con el fin buscado y la acción de denunciar falsamente (conclusión parcial 3).

- También podría ocurrir que la menor, al tener contacto con Fray Huacho o la familia de este, haya podido ser manipulada o influenciada para que cambie su versión sobre los hechos. Sin embargo, desde que se formuló la denuncia indicó que no tuvo ninguna comunicación, contacto o cercanía con Fray Huacho (la agraviada, su hermana y su abuela indican que esta 
persona estuvo en el pueblo por un periodo corto, en que laboró en una obra de construcción, y después se fue, sin que sepan nada de él), lo que es corroborado por esta persona, quien negó haber vivido en el lugar donde ocurrieron los hechos por un tiempo mayor al que trabajó en el lugar. Distinto sería el caso si Fray Huacho fuese un familiar o allegado de la menor, pues allí podría haber presionado a esta o su familia, o haberles ofrecido alguna dádiva para que se retracten. Esto nos permite concluir que tampoco existieron probados contactos entre la menor y su presunto agresor, que permitan inferir que fue manipulada o influenciada para que cambie su versión sobre los hechos o se retracte (conclusión parcial 4).

- Un último elemento a considerar es que con la detención o liberación de Huacho no se afecta a la menor, pues ella no tenía ningún vínculo de dependencia económica, afectiva o familiar con esta persona, lo que si ocurría con Iván Villaizan, pues este era su conviviente y padre del hijo que la menor esperaba. Además, vivía con la familia de esta persona y señaló que el abogado Percy Coronado la conminó a sindicar a Fray Huacho, porque no identificarían ni ubicarían a esta persona, en la medida que no era del lugar, nadie lo conocía y se encontraba lejos. De este modo, la intensidad de las consecuencias negativas generadas con la denuncia en el plano económico, afectivo o familiar de la menor son pequeñas o insignificantes (conclusión parcial 5).

De este modo, la nueva hipótesis (H5) puede ser descartada, en la medida que presenta numerosos puntos débiles. Asimismo, el análisis descrito también permite descartar $\mathbf{H} \mathbf{1}^{13}$ y corroborar H3, pues - de un lado- ninguno de los nuevos elementos actuados permite sostener que la menor convivió (D4) y fue agredida sexualmente por Fray Huacho (D2) y, de otro lado, estos nuevos elementos hacen posible concluir que la menor convivió (D4), fue agredida sexualmente por Iván Villaizan (D2) y quedó embarazada de este (D1), y que el abogado Percy Coronado y la familia de Iván Villaizan la conminaron para que mienta y así su pareja sentimental pueda quedar libre.

De modo que, nuevamente, después de haber pasado de las pruebas a las hipótesis y, luego, de las hipótesis a las pruebas, podemos concluir que la mejor explicación del caso o la hipótesis definitiva es $\mathbf{H 3}$.

13 Esta también fue la conclusión de la Corte Suprema de Justicia, que absolvió a Fray Huacho de la acusación formulada en su contra por la presunta comisión del delito de violación sexual de menor de edad. 
Ahora bien, este análisis también podría graficarse de similar forma a la realizada en el primer caso. Sin embargo, consideramos más importante resaltar otro aspecto: el análisis abductivo del caso también nos permitió elaborar un diseño institucional que nos permite aproximarnos a lo que probablemente sucedió (o tal vez, incluso, a la verdad del caso), donde se consideran todas las conclusiones parciales a las que se arribó en el análisis de confirmación o rechazo que se hizo de H5. De este modo, para estimar como válida la retractación de una presunta víctima de un delito sexual - a futuro- pueden evaluarse los siguientes aspectos:

1. La solidez o debilidad de la declaración incriminatoria, a la luz de los elementos corroborativos actuados.

2. La coherencia interna y exhaustividad del nuevo relato y su capacidad corroborativa.

3. La razonabilidad de la justificación de haber brindado una versión falsa o errónea, verificando la proporcionalidad entre el fin buscado y la acción de denunciar falsamente.

4. Los probados contactos que haya tenido o podido tener el investigado con la víctima, que permitan inferir que esta haya sido manipulada o influenciada para cambiar su versión.

5. La intensidad de las consecuencias negativas generadas con la denuncia en el plano económico, afectivo y familiar de la presunta agraviada ${ }^{14}$.

El razonamiento sobre todos estos aspectos se materializa en un discurso justificativo, pero se va elaborando a través de un complejo proceso de descubrimiento, en el que la formulación de hipótesis y su proceso de corroboración se retroalimentan constantemente. Ello, nuevamente, muestra cómo no solo a nivel teórico-conceptual, sino también a nivel práctico, corresponde debilitar la distinción tajante entre $\mathrm{CD}$ y CJ a la que hemos hecho referencia a lo largo de este artículo.

Finalmente, es importante mantener cautela sobre las conclusiones que se pueden extraer de nuestro análisis. Esta cautela se fundamenta, principalmente, en dos motivos: en el hecho de que se trata de una reconstrucción racional que omite algunos aspectos procesales y en el hecho de que el análisis que hemos realizado se refiere a la estructura de la inferen-

\footnotetext{
14 Estos elementos fueron recogidos por las Salas Penales Permanente y Transitorias de la Corte Suprema de Justicia de la República del Perú en el Acuerdo Plenario N. ${ }^{\circ} 1-2011 / C J-116$. En el ejemplo comentado se volvió a insistir en estos elementos y analizó el caso a la luz del mencionado Acuerdo Plenario.
} 
cia abductiva del caso, más no a la satisfacción (o no satisfacción) del estándar de prueba relevante. Este último aspecto es fundamental para la determinación de la calidad de la explicación ofrecida por la que incluso podría ser la mejor hipótesis dentro de las disponibles.

\section{Conclusiones}

La principal conclusión a la que arribamos es que la dicotomía CJ/CD ha ido perdiendo fuerza progresivamente. Ello se ha producido tanto por avances en la discusión al seno de la filosofía de la ciencia, como por los avances en la teoría del derecho y de la argumentación jurídica. En este último ámbito se entiende, ahora, que en la justificación hay componentes propios del descubrimiento. Los ejemplos puestos sobre el proceso de interpretación de enunciados normativos, así como los referidos a la generación y justificación de hipótesis probatorias, lo confirman.

Asimismo, a grandes rasgos, el proceso de descubrimiento se puede desarrollar a través de una "lógica del descubrimiento", expresión que puede hacer alusión tanto a una metodología para el análisis, como a un tipo de inferencia que corresponde especialmente al proceso de descubrimiento. En el segundo de estos sentidos, la inferencia buscada es de tipo abductivo. Precisamente el presente artículo avanzó una propuesta de caracterización del razonamiento abductivo que, además de salvar críticas formuladas contra otras versiones de dicho razonamiento, es especialmente fructífera para la comprensión del razonamiento probatorio.

Finalmente, los ejemplos propuestos, recientemente resueltos por la Corte Suprema de Justicia peruana, muestran cómo la abducción, primero, nos permitió dotar de racionalidad al contexto de descubrimiento y, segundo, cómo el análisis de casos en concreto, en el marco de un análisis abductivo, nos permitió elaborar un diseño institucional para acercarnos a la verdad. Además, nos ayudó a disipar y superar el divorcio que suele existir entre la teoría, los diseños intelectuales y la práctica jurisprudencial de los juzgados, de modo tal que fue posible que ambos ámbitos puedan colaborar de forma fructífera. 


\section{Referencias}

Accatino, D. (2002). Notas sobre la aplicación de la distinción entre contextos de descubrimiento y de justificación al razonamiento judicial. Revista de Derecho, (13): 9-25.

Aliseda, A. (2006). Abductive Reasoning. Logical Investigations into Discovery and Explanation. Springer.

Anderson, B. (1996). "Discovery" in Legal Decision-Making. Springer.

Arabatzis, T. (2006). On the inextricability of the context of discovery and the context of justification. En: J. Schikore, \& F. Steinle (eds.), Revisiting Discovery and Justification: Historical and philosophical perspectives (pp. 215-230). Springer.

Atienza, M. (2020). What is the Theory Legal Argumentation for? International Journal for the Semiotics of Law, (33): 147-153.

Atienza, M. (2017). Algunas tesis sobre el razonamiento judicial. En Aguiló, J. \& Grández Castro, P. (eds.), Sobre el razonamiento judicial. Una discusión con Manuel Atienza (pp. 11-42). Palestra.

Atienza, M. (2013). Curso de argumentación jurídica. Trotta.

Bonorino Ramírez, P. R. (2014). Ni deducción ni inducción: abducción. En: J. García Amado \& P. Bonorino Ramírez (Coords). Prueba y razonamiento probatorio en el Derecho. Debates sobre la abducción (pp. 163-187). Comares.

Canale, D. (2019). En busca de lo implícito. Ensayos sobre razonamiento e interpretación en el Derecho. Universidad Externado de Colombia.

Douven, I. (2017a). Abduction. En: Zalta, E. (ed.), The Stanford Encyclopedia of Philosophy. Recuperado de: https://plato.stanford.edu/archives/sum2017/entries/abduction/

Douven, I. (2017b). Peirce on Abduction (Supplement to Abduction). En: Zalta, E. (ed.), The Stanford Encyclopedia of Philosophy. Recuperado de: https://plato.stanford. edu/entries/abduction/peirce.html

Fann, K. (1970). Peirce's Theory of Abduction. Martinus Nijhoff.

Ferrer Beltrán, J. (2007). La valoración racional de la prueba. Marcial Pons.

Frankfurt, H. (1958). Peirce's Notion of Abduction. Journal of Philosophy, (55): 593-596.

Gascón Abellán, M. (2014). ¿Lógica del descubrimiento para la prueba? En: García Amado, J. y Bonorino, P. (eds.), Prueba y razonamiento probatorio en Derecho. Debates sobre abducción (pp. 149-162). Comares. 
Gascón Abellán, M., \& García Figueroa, A. J. (2015). La argumentación en el Derecho. Algunas cuestiones fundamentales (2da. ed.). Palestra.

Guastini, R. (2018). Interpretar y argumentar (2da. ed.). Centro de Estudios Políticos y Constitucionales.

Hoyningen-Huene, P. (2006). Context of Discovery versus Context of Justification and Thomas Kuhn. En: Revisiting Discovery and Justification: Historical and Philosophical perspectives on the context distinction (pp. 119-131). Springer.

Kaufmann, A. (1999). Filosofía del Derecho. Universidad Externado de Colombia.

Kraus, M. (2003). Charles S. Peirce's Theory of Abduction and the Aristotelian Enthymeme from Signs. En: Van Eemeren, F; Blair, J. A.; Willard, C.; Snoeck, F. (eds.), Anyone who has a view. Theoretical contributions to the study of argumentation (pp. 237254). Springer.

Lifante, I. (2019). En defensa de una concepción constructivista de la interpretación jurídica. Revus. Journal for Constitutional Theory and Philosophy of Law, 39, pp. 1-21. DOI: $10.4000 /$ revus. 5423

MacCormick, N. (2003[1978]). Legal Reasoning and Legal Theory. Oxford Clarendon Press.

Niiniluoto, I. (2018). Truth-Seeking by Abduction. Springer.

Popper, K. (2017). La lógica de la investigación científica (2da. ed.). Tecnos.

Pino, G. (2017). La teoría del razonamiento judicial de Manuel Atienza. Notas al margen. En Aguiló, J. \& Grández Castro, P. (eds.), Sobre el razonamiento judicial. Una discusión con Manuel Atienza (pp. 305-327). Palestra.

Reichenbach, H. (1938). Experience and Prediction. An Analysis of the Foundations and the Structure of Knowledge. The University of Chicago Press.

Schickore, J. (2018). Scientific Discovery. En: Zalta, E. (ed.), The Stanford Encyclopedia of Philosophy. Recuperado de: https://plato.stanford.edu/archives/sum2018/entries/ scientific-discovery/

Schikore, J. \& Steinle, F. (2006). Introduction: revisiting the context distinction. En: Revisiting Discovery and Justification: Historical and Philosophical perspectives on the context distinction (pp. vii-xix). Springer.

Sotomayor, J. E. (2021a). Apuntes históricos, conceptuales y jurisprudenciales sobre el deber de motivación de las resoluciones judiciales. En: Alvites, E. (coord.), La Constitución frente a la sociedad contemporánea. Treinta años de la Maestría en Derecho Constitucional de la Pontificia Universidad Católica del Perú (pp. 23-52). PUCP. 
Sotomayor, J. E. (2021b). Argumentación jurídica: una introducción. Zela.

Taruffo, M. (2006). La motivación de la sentencia civil. Tribunal Electoral del Poder Judicial de la Federación.

Tuzet, G. (2021). Filosofía de la prueba. Marcial Pons.

Tuzet, G. (2014). Usos jurídicos de la abducción. En: García Amado, J. y Bonorino, P. (eds.), Prueba y razonamiento probatorio en Derecho. Debates sobre abducción (pp. 121-147). Comares.

Walton, D. (2005). Abductive Reasoning. The University of Alabama Press. 